\title{
Pulmonary asbestos and dust content in East Anglia
}

\author{
PGI STOVIN, P PARTRIDGE \\ From Papworth Hospital, Papworth Everard, Cambridge
}

\begin{abstract}
Measurements were made of the asbestos fibre and dust content of samples from 96 surgically excised lungs; 42 necropsies on patients with lung cancer, 11 necropsies on patients with non-pulmonary malignancies, and 59 necropsies on patients without any malignant disease. The patients' ages ranged from 45 to 74 years at the time of study. None of the patients had asbestosis. The distribution of fibres and dust content of the lungs showed a log-normal distribution. There was no significant difference in fibre counts or dust content between men and women, and between lung cancer and non-cancer patients. The only group with an association with a high asbestos fibre count was four necropsy cases of pleural mesothelioma. There was no significant relationship between asbestos fibre count and dust content of the lung. The present data suggest that asbestos fibre counts below 100000 per gram of dried lung are not related to specific asbestos disease, although in the surgical cases who were closely questioned on their residential and occupational histories most of those with fibre counts above 30000 per gram dried lung had had occasions of definite or very likely asbestos exposure.
\end{abstract}

The rare studies of the dust and asbestos fibre content of the normal English lungs have shown from 2.5 to $7.5 \mathrm{~g}$ of dust in the right lung 1 or 0.7 to $14.8 \mathrm{~g}$ per $100 \mathrm{~g}$ of dried lung, ${ }^{23}$ and $85 \%$ of an urban population had asbestos fibre counts below 50000 per $\mathrm{g}$ dried lung.4

In a study of seven Pittsburg residents, Gross and colleagues ${ }^{5}$ found 0.6 to $2.7 \mathrm{~g}$ dust per $100 \mathrm{~g}$ dried lung and 300 to 3900 ferruginous bodies per $g$ dried lung. Not all the ferruginous bodies however were asbestos bodies.

One hundred surgically resected lungs and 112 necropsy lungs drawn from Cambridgeshire and parts of adjacent counties were studied to try and assess the extent of exposure to asbestos.

\section{Methods}

The surgical specimens were selected as having some normal lung but otherwise were consecutive. Four of these 100 cases were 24 to 36 years old with 1600 to 4900 asbestos fibres and 12 to $106 \mathrm{mg}$ dust per $\mathrm{g}$ dried lung. The other 96 were aged 45 to 74 years, as were all the 112 necropsy cases. These four youngest surgical cases have been excluded from the analyses of the rest of this paper because there were no matching necropsy cases.

Address for reprint requests: Dr PGI Stovin, Sims Woodhead Memorial Laboratory, Papworth Hospital, Papworth Everard, Cambridge CB3 8RE.
All but four of the 96 surgical cases had bronchogenic carcinoma. These four had emphysema, pulmonary embolism, a vascular hamartoma, and a pseudolymphoma. Fifty nine of the 112 necropsy cases had no malignant disease. The 53 patients with malignant disease comprised 42 with lung cancer, four with mesotheliomas, and seven with nonpulmonary cancers.

The technique was based on that of Whitwell et $a l^{4}$ and all results are expressed per gram of dried normal lung. All the lungs were inflated with $10 \%$ formol saline prepared from usual reagent grade materials and tap water and stored in a large polypropylene container. After fixation two adjacent portions of the most dependent normal peripheral lung about 8 cubic centimetres each in size are taken and allowed to drain off their excess formol saline by standing two minutes on absorbent paper towelling before being put into plastic $30 \mathrm{ml}$ conical based containers. The wet weight of each piece was recorded. One piece was dried for three days at $60^{\circ} \mathrm{C}$ and then reweighed. The other piece was digested in $10 \mathrm{ml} 40 \% \mathrm{KOH}$ at $60^{\circ} \mathrm{C}$. This digestate was then diluted with $20 \mathrm{ml}$ particle free fluid (Isoton Coulter Electronics) and centrifuged at 3600 rpm for 25 minutes. The supernatant fluid was removed and the black deposit was resuspended in a measured volume of Isoton (between 2 and $5 \mathrm{ml}$ ) to give a countable density of particles in the four Fuchs Rosenthal chambers which were used for 
counting coated and uncoated straight or curved asbestos fibres using phase contrast microscopy to show up the uncoated fibres. Only asbestos fibres longer than $8 \mu \mathrm{m}$ were counted. After the filling of the chambers the suspension was recentrifuged, the supernatant was removed, and the black dust deposit was dried at $60^{\circ} \mathrm{C}$ and then weighed. It was assumed that the removal of about $10 \mathrm{~mm}^{3}$ of suspended dust was compensated by the increased weight from residual salts added in the formol saline, $\mathrm{KOH}$ and Isoton.

All the surgical patients who had lung samples estimated were interviewed before discharge from hospital when a detailed residential occupational and smoking history was taken. No such detailed information was available in the necropsy cases in whom usually only the occupation at the time of hospital admission was recorded.

\section{Results}

After an initial period of cross checking the counts, the surgical and necropsy material were analysed independently. Despite the standardisation of methods there were appreciable differences between the two groups. Four out of the 100 surgical cases (PGIS) had no detectable asbestos fibres; in contrast 35 of the 112 necropsy cases (PP) had no detectable fibres, $13(31 \%)$ in those with lung cancer and 22 $(37 \%)$ in those without lung cancer. The lowest level of detection achieved was 800 asbestos fibres per gram of dried lung and there were only two other counts of 1000 or lower.

The probability that there was an undercounting of uncoated asbestos fibres in the necropsy series is also suggested by the higher ratio of coated to noncoated fibres in the necropsy cases (1.01 mean ratio) than in the surgical cases $(0.46$ mean ratio). There was no significant difference between the ratio in necropsy cancer $(0 \cdot 83)$ and non-cancer cases $(1 \cdot 16)$. Throughout the rest of this paper fibre counts are the sum of coated and uncoated asbestos fibres.

Direct comparison between the two series was possible in six of the surgical patients who subsequently came to necropsy. The asbestos fibre counts
Table 1 Comparison of fibre count and dust content in the same patient at surgical resection and necropsy

\begin{tabular}{llllll}
\hline Case number & \multicolumn{2}{c}{ Fibre count $/ g$ dry lung } & & \multicolumn{2}{c}{ Dust mg/g dry lung } \\
\cline { 5 - 6 } & Surgical & Necropsy & & Surgical & Necropsy \\
\hline $14 / 98$ & 1300 & nil & 50 & 13 \\
$61 / 109$ & 2200 & nil & 159 & 11 \\
$38 / 94$ & 5600 & 10900 & 27 & 29 \\
$78 / 7$ & 20100 & 11900 & 83 & 201 \\
$55 / 19$ & 21200 & 24800 & 78 & 4 \\
$64 / 18$ & 23300 & 14200 & 146 & 44 \\
\hline
\end{tabular}

Table 2 Triplicate fibre counts on three adjacent pieces of one lung

\begin{tabular}{llll}
\hline Sample A & 30700 & 24600 & 28600 \\
Sample B & 28800 & 26600 & 24400 \\
Sample C & 31600 & 29400 & 31600 \\
\hline
\end{tabular}

Average count 28 500, SD 2800.

Table 3 Duplicate samples

\begin{tabular}{|c|c|c|c|c|c|}
\hline \multicolumn{2}{|c|}{ Case number } & \multicolumn{2}{|c|}{ Fibre count/g dry lung } & \multicolumn{2}{|c|}{ Dust mg/g dry lung } \\
\hline & & Count 1 & Count 2 & Count 1 & Count 2 \\
\hline Surgical & $\begin{array}{l}12 \\
46 \\
49 \\
69 \\
78\end{array}$ & $\begin{array}{r}3300 \\
1700 \\
50000 \\
3900 \\
22100\end{array}$ & $\begin{array}{r}6500 \\
1400 \\
88500 \\
9000 \\
22600\end{array}$ & $\begin{array}{r}57 \\
125 \\
17 \\
145 \\
83\end{array}$ & $\begin{array}{r}90 \\
186 \\
52 \\
79 \\
71\end{array}$ \\
\hline Necropsy & $\begin{array}{r}79 \\
103 \\
106 \\
111\end{array}$ & $\begin{array}{l}\text { nil } \\
\text { nil } \\
\text { nil } \\
\text { nil }\end{array}$ & $\begin{array}{c}1800 \\
\text { nil } \\
1900 \\
\text { nil }\end{array}$ & $\begin{array}{l}- \\
46 \\
40 \\
41\end{array}$ & $\begin{array}{l}80 \\
46 \\
14 \\
13\end{array}$ \\
\hline
\end{tabular}

and dust content of the surgical and necropsy specimens are shown in table 1 . There is reasonable agreement between the two estimates for fibres and less so for dust content.

In one lung three adjacent pieces were estimated in triplicate for fibre count. These are shown in table 2. Agreement was good between samples. Duplicate samples were assayed for asbestos fibre and dust content in five surgical and four necropsy cases and they (table 3) show the same level of agreement between samples as between surgical and necropsy specimens seen in table 1 .

In five necropsy cases selected for having a reasonable number of asbestos fibres, fibres were counted in five different segments. It will be seen from table 4 that there is up to an eight-fold difference

Table 4 Fibre counts/g dry lung in five sites

\begin{tabular}{|c|c|c|c|c|c|}
\hline \multirow[t]{2}{*}{ Site } & \multicolumn{5}{|c|}{ Necropsy case number } \\
\hline & 19 & 20 & 90 & 110 & 113 \\
\hline Upper lobe apex & 46100 & 974600 & 21800 & 437900 & 22500 \\
\hline Lower anterior upper lobe & 42900 & 2300700 & 22500 & 49500 & 36700 \\
\hline Lower lobe apex & 13300 & 1725500 & 25100 & 269600 & 12300 \\
\hline Anterior basal & 17500 & 2492400 & 24400 & 138700 & 8900 \\
\hline Posterior basal & 10000 & 1093100 & 21900 & 210300 & 14800 \\
\hline Mean & 26000 & 1717300 & 23100 & 221200 & 19000 \\
\hline SD & 15300 & 613600 & 1400 & 130900 & 9900 \\
\hline Initial single sample & 24800 & 1780700 & 22500 & 499800 & 43500 \\
\hline
\end{tabular}




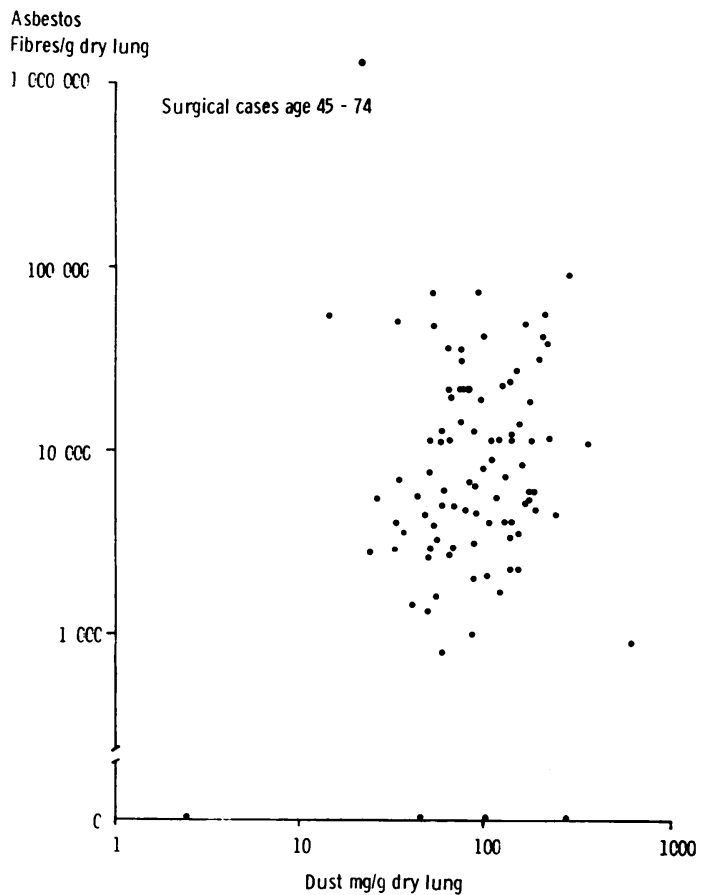

Fig 1 Asbestos fibre counts plotted against dust content of surgical lungs.

between the segment with the lowest and highest counts. In only one of the five cases was there uniformity of distribution of fibres between the segments. There was no part of the lung that was consistently rich or consistently poor in fibres. As a working rule in selecting material for $\mathrm{KOH}$ digestion throughout this study the lowest part of the lobe or lung with normal parenchyma was chosen. None of the lungs studied showed any interstitial fibrosis of asbestosis.

Although there were differences between the surgical and necropsy cases with fewer uncoated fibres and more cases with undetectable fibres in the necropsy series than in the surgical, it cannot be entirely explained by observer variability because in the cases in which direct comparison was possible the variation in counts and dust content were no greater than the variation recorded by each observer for the duplicate specimen analyses (table 3 ).

In the surgical as in the necropsy cases there was no increase in asbestos fibre or dust content in the lungs with increasing age. Figures 1 and 2 also show that there is no correlation between asbestos fibre and dust content of the lungs. These observations indicate that there is unlikely to be any general atmospheric pollution with asbestos in East Anglia.

There were 14 women in the surgical series, 13 of whom had lung cancer and one a pseudolymphoma. In the necropsy series 25 were women, of whom nine had primary lung cancer, one had a mammary carcinoma and 15 had no malignant disease. Figures 3 and 4 show that there was no significant difference in fibre counts or in dust count between males and females, even though in the surgical carcinoma and the necropsy non-carcinoma subsets the upper end of the male fibre counts were higher than for the females, and the male necropsy noncarcinoma subset had a low median asbestos fibre count.

There were no significant differences (figs 3 and 4) in the range of fibre counts or of dust content between the lung cancer and the non-cancer cases. However, the male necropsy non-cancer group had the highest proportion $(50 \%)$ of undetectable fibre counts compared to $39 \%$ for the male necropsy cancer and $5 \%$ for the male surgical lung cancer cases.

Among the necropsy cases there were 11 patients with neoplasms other than carcinoma of the lung. Four of these 11 had pleural mesothelioma; the remainder were single cases of carcinoma of the pyriform fossa, oesophagus, pancreas, kidney,

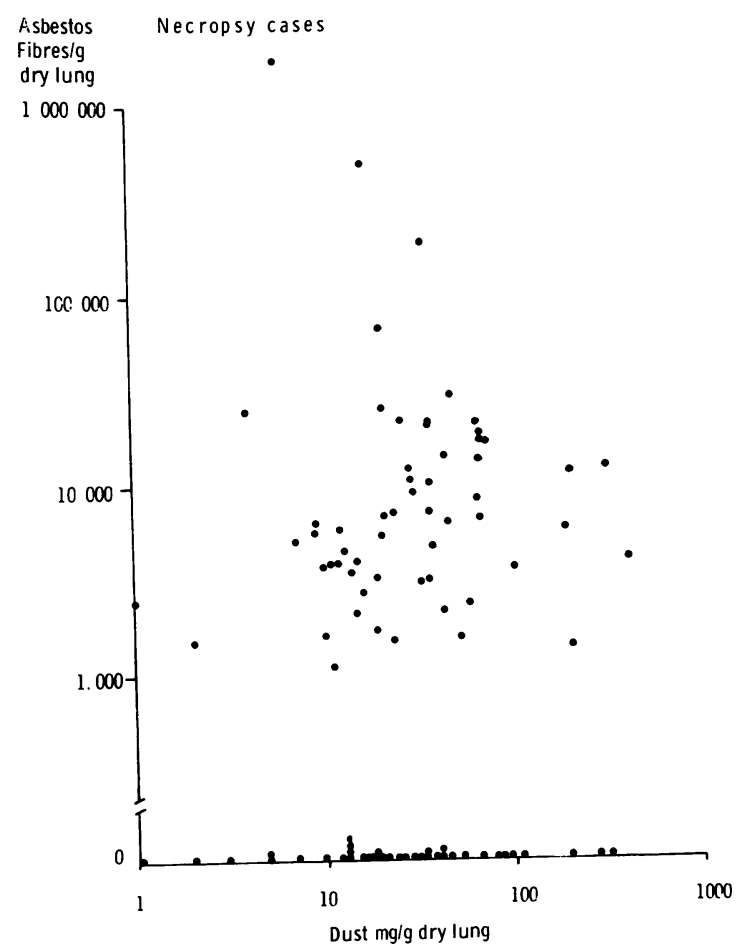

Fig 2 Asbestos fibre counts plotted against dust content of necropsy lungs. 


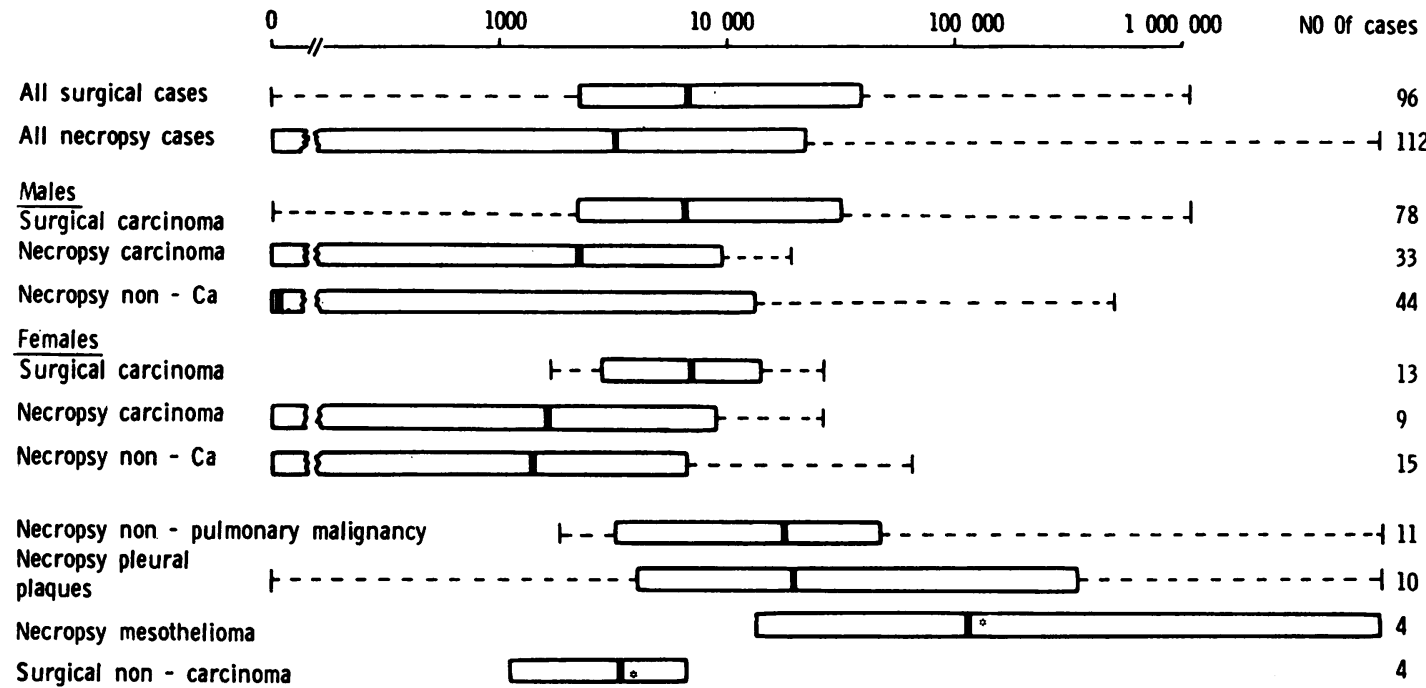

Box shows median \& central $\% / 3$ of range of fibre counts except which shows median and full range

r-..-t Full range

Fig 3 Asbestos fibre counts by type of patient.

Dust $\mathrm{mg} / \mathrm{g}$ dry lung

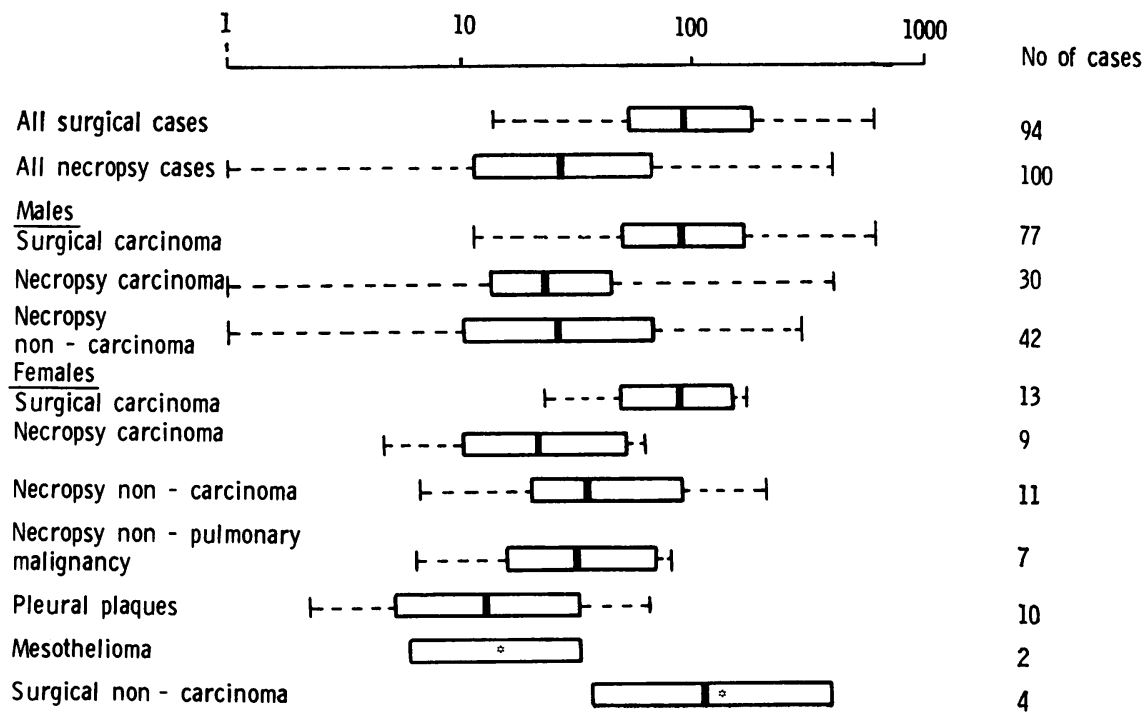

Fig 4 Dust content by type of patient. 
Table 5 Occupations of surgical cases with highest fibre counts

\begin{aligned} & \hline Fibre count Occupations \\ & \hline 236400 Boiler lining-brick layer, railway wagon repairs \\ & 85100 Electrician mainly on boiler installation, gas works \\ & 72700 Bakerlite and Diethyl plastics moulding, welding \\ & firm clerk \\ & 55700 Railway shunter, metal lathe worker \\ & 55600 Building demolition, carpenter, metal grinder \\ & 50800 Boiler lagger, stoker, brick moulder \\ & 49700 Building labourer, farm labourer \\ & 46700 Building labourer, flour mill \\ & 41800 Building labourer, farm labourer \\ & 40700 Railway shunter, foundry mould maker, welder \\ & 38200 Stone mason, foundry worker, asbestos roofing \\ & 36400 Electronics research-soldering and glues \\ & 34800 Grocer, car maintenance \\ & 31200 Demolition, driver \\ & 30900 Plastic moulding, firework maker, tyre retreads, \\ & welder \\ & 27100 Vegetable sorter, bar maid \\ & \hline\end{aligned}

bladder and breast, and astrocytoma. The four mesotheliomas had asbestos fibre counts ranging from 14400 to 1780700 per g dried lung with a median count of 116200 . The fibre count for this group is significantly higher than in any other group of cases. The dust content of the mesothelioma lungs is not different from any of the other groups (fig 4). The occupations of these four mesothelioma cases were given as police sergeant, retired bricklayer, retired machine operator, and maintenance engineer.

Nine male and one female necropsy patients had hyaline fibrotic pleural plaques. Four of these cases had lung cancer and three had mesothelioma. The asbestos fibre counts and dust content are shown in figs 3 and 4.

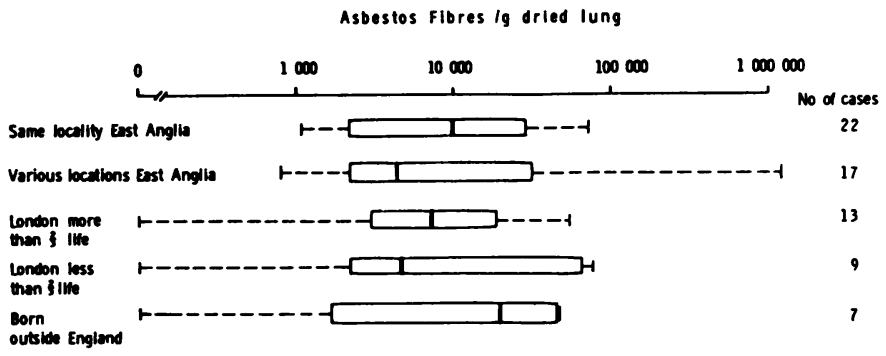

Fig 5 Asbestos fibre count by residence of patient.

There were only two types of carcinoma present in reasonable numbers for analysis. Fifty-eight of the surgical cases and 15 of the necropsy cases were squamous cell carcinoma and adenocarcinoma was present in 20 of the surgical cases and 17 of the necropsy cases. The asbestos fibre counts and dust content of these cases were not statistically significantly different (figs 7 and 8). Seven per cent of the surgical squamous cell carcinomas were women compared with $14 \%$ in the necropsy series. Among the adenocarcinomas $20 \%$ of surgical and $31 \%$ of the necropsy cases were women.

Fig 6 Dust content by residence of patient.

Detailed occupational histories were taken in the surgical group. The 16 cases with the highest frequent occupation in this group was building labourer with demolition work forming a substantial experience had asbestos fibre counts in the central two-thirds of the total surgical group. The two cases inding ingly handled any asbestos additives to the plastics.

The highest dust content was in the lung of a clerk maintainer.

In the surgical cases 22 had lived all their lives in the same town or village apart from war service. A further 17 had moved but remained in East Anglia. Nine had been born in London but moved to East lives in London before moving to Cambridgeshire. eases were born outside England. The asbestos fibre and dust content of the lungs in these residential groups are shown in figs 5 and 6 and there is no difference between them.

The smokers averaged 57 pack-years ( + SD 40) and there was no significant difference in the lung and the heavy smokers (more than 98 pack-years). Unfortunately the smoking and occupational histories were incomplete for the necropsy patients, so no meaningful analysis was possible.

Same locality East Anglia
Various locations East Anglia
London more than 3 life




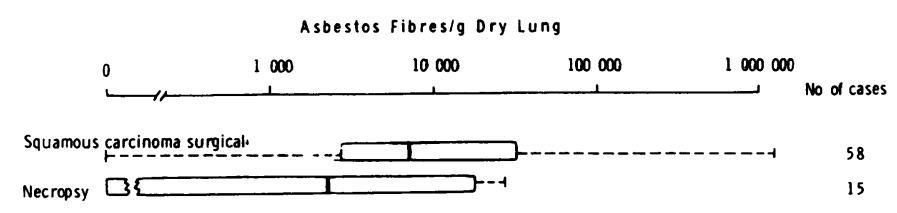

Adenocarcinoma surgical

Necropsy $[2 \longrightarrow---1$
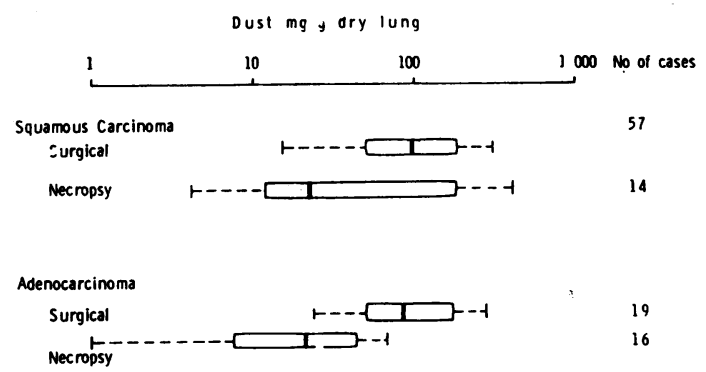

Fig 8 Dust content by type of carcinoma.

\section{Discussion}

This study shows that neither asbestos fibre counts or dust content show a normal distribution. The distribution is more satisfactorily examined on a $\log$ normal distribution. Tipton and Cook $^{6}$ and Sweet et $a l^{7}$ regarded the median count as a more reliable estimate of the central tendency than the mean. Accordingly the figures show our data on a $\log$ scale with the median, the central $66 \%$, and the total range for each of the items analysed.

The figures for the dust content of the lungs in the present study were comparable to those given for English coal ${ }^{12}$ and haematite ${ }^{3}$ miners without silicosis and for 100 Cincinnati hospital patients and coal miners. ${ }^{7}$ These latter authors ${ }^{7}$ found no significant effect of age or sex on the total dust content of the lungs, and we also observed no significant relationship of total dust content to sex or age in our East Anglian patients.

The effects of age and sex on the asbestos fibre count in the lung are not fully established and may depend in part on the method of assay. Most authors $^{8-10}$ found no effect of age, but Cauna et al ${ }^{11}$ observed a decreasing incidence of asbestos bodies with age, while there are a few who suggest a peak age incidence in the $70 \mathrm{~s}^{12}$ or $40 \mathrm{~s} .{ }^{13}$ Our own observation is that there is no significant effect of age on the asbestos fibre count. This would seem to suggest that there is no general background exposure but that the opportunities for occasional exposure may
Fig 7 Asbestos fibre count by type of carcinoma.

$$
\begin{aligned}
& 20 \\
& 17
\end{aligned}
$$

be increasing so that the younger age group have the same counts as the older age group.

The prevalence of asbestos bodies has been described as lower in women than in men ${ }^{9-12}$ although Utidjian et $a l^{14}$ found no difference. These differences may be in part related to the level of asbestos fibre count in the lung in that Rosen et al ${ }^{9}$ reported an equal incidence in men and women at counts of fewer than 60 ferruginous bodies per $5 \mathrm{~g}$ of lung, and Whitwell et al ${ }^{4}$ found twice the frequency of men than of women with asbestos fibre counts greater than 20000 per gram. In the present series the male:female ratio in the cases above and below asbestos fibre counts of 20000 shows an inconstant pattern. Among the surgical cases the ratio changes from 5:1 below 20000 fibres per gram to 10:1 above this count. In the necropsy lung cancer group the ratios are $4: 1$ and $2: 1$, while in the necropsy non-malignant group the ratios are $2: 1$ and $4: 1$ respectively.

It is difficult to separate occupational from nonoccupational exposure to asbestos. Even with detailed questioning the patient does not always remember exposure or never knew the nature of what he or she was working with. Whitwell et al ${ }^{4}$ deduced that asbestos fibre counts above 20000 per gram dried lung was suggestive of occupational exposure and that 50000 or more was virtually certainly so. Warnock and Churg ${ }^{15}$ reached a similar conclusion using 2200 ferruginous bodies per $g$ of wet lung as the dividing level between occupational and nonoccupational exposure. To assess the comparability of these two groups of authors' 15 counting methods we noted that the wet weight of our samples was on average 10.125 times the dry weight $(S D \pm 3.49$ times) and that the ratio of coated to uncoated fibres were on average 1.01 and 0.46 depending on whether the series is necropsy or surgical material. Thus if our material is applicable to Whitwell et al ${ }^{4}$ and Warnock and Churg ${ }^{15}$ it suggests that the latter's level of 2200 ferruginous bodies per gram wet weight is comparable to Whitwell et al's 50000 asbestos fibres per gram dry weight. Our own cases suggest that industrial exposure results in asbestos 
fibre counts over 30000 per gram dry weight.

The similarity in these figures between different observers is remarkable in view of the differences between the two observers of this paper (table 1) and the ten-fold difference between four observers counting $30 \mu \mathrm{m}$ sections reported by Oldham ${ }^{16}$ and in view of our finding as much as a nine-fold difference in asbestos fibre counts between different areas of the same lung. It is also interesting that Ashcroft and Heppleston ${ }^{17}$ found a mean ratio of coated to uncoated fibres of 0.43 in their necropsy series which is very similar to our surgical series.

There appears to be no area in East Anglia for high asbestos or dust exposure and it is of interest that the asbestos fibre counts and dust content are no better or worse for those that have lived all their life in East Anglia compared with those that have lived most of their lives in London.

The distribution of asbestos fibres in the lung is not properly understood. In three of 14 cases Rosen et $\mathrm{al}^{9}$ found no asbestos bodies in one of the lobes examined and in two of these three it was the left lower lobe that had no bodies in it. Dick and Naylor ${ }^{18}$ observed that if only one lobe had been examined in their cases then evidence of asbestos exposure would have been found in more cases if the upper lobe than the lower lobe had been sampled. The cases we analysed showed no consistent lobar or segmental preference but this may be that a selective distribution can only be seen at low levels of exposure and our five cases in table 4 were selected for high counts to improve the accuracy of counting.

Although our necropsy non-cancer group had more cases with no detectable asbestos fibres than in the necropsy or surgical cancer groups, the median and central two-thirds range of the asbestos fibre counts were not significantly different in any of the three groups. Within the exposure range observed in our cases we must argue that we have found no evidence that levels of asbestos fibres at a median count of 11000 is related to the presence of lung cancer. This is in line with the observations of other authors. ${ }^{4} 9101213$ Though Warnock and Churg ${ }^{15}$ have argued otherwise, their evidence is questioned because of the different proportion of women in their control and test groups.

The median asbestos fibre count of 12000 per gram dried weight in cases with hyaline fibrotic pleural plaques is not different from the median counts in our carcinoma and non-carcinoma cases. However, this is not the case with our four cases of mesothelioma who had a median count of 116200 asbestos fibres per gram. Although this level of count is not as high as the median count of 750000 asbestos fibres per gram for 100 mesotheliomas found by Whitwell and colleagues, ${ }^{4}$ it is well above the minimal count for industrial exposure.

In the study on hyaline pleural plaques ${ }^{19}$ one-third of cases had relatively few asbestos bodies in their lung and no evidence of occupational asbestos exposure. Using a less sensitive method $14 \%$ of patients with hyaline plaques had demonstrable asbestos bodies in their lungs and the plaques were present in $33 \%$ of randomised hospital necropsies. ${ }^{20}$ Only one of our patients with pleural plaques had no asbestos fibres; this case and two others had no pulmonary or pleural malignancy. Our view is that plaques give a good indication of asbestos exposure but no indication of the severity of this exposure.

Whitwell et al ${ }^{21}$ suggested that there might be an increased incidence of adenocarcinoma of the lung in asbestosis. Warnock and Churg ${ }^{15}$ observed an increased proportion of adenocarcinomas in their cases with the higher number of ferruginous bodies. At the level of asbestos fibre counts in our cases we found no difference in median counts between the squamous and adenocarcinoma cases.

Our tentative conclusions are that in the general population of East Anglia non-occupational exposure to asbestos is not occurring as a continuing background experience but probably represents occasional short episode(s) of exposure, and these episodes result in fibre counts up to about 30000 per $\mathrm{g}$ dried lung. Above this level exposure is likely to be occupationally related and above about 100000 there is likely to be asbestos related lung disease. The non-asbestos-fibre dust was made up mainly of fine black carbon particles and as with the asbestos fibres there was no evidence of a continuing background experience nor could we relate it to cigarette consumption.

We wish to thank the Regional Health Authority for funding this research, Mrs PA Porter for secretarial help, and Mrs M Thorburn for preparing the figures.

\section{References}

${ }^{1}$ Rivers D, Wise ME, King EJ, Nagelschmidt G. Dust content, radiology and pathology in simple pneumoconiosis of coal workers. Br J Ind Med 1960;17:87-108.

${ }^{2}$ Fauids JS, King EJ, Nagelschmidt G. The dust content of the lungs of coal workers from Cumberland. $\mathrm{Br} J$ Ind Med 1959;16:43-50.

${ }^{3}$ Faulds JS, Nageischmidt GS. The dust in the lungs of haematite miners from Cumberland. Ann Ocsup $\mathrm{Hyg}$ $1962 ; 4: 255-63$.

+ Whitwell F, Scott J, Grimshaw M. Relationship between occupations and asbestos-fibre content of the lungs in patients with pleural mesothelioma, lung cancer and other diseases. Thorax 1977;32:377-86.

${ }^{5}$ Gross P, Tuma J, de Treville RTP Fibrous dust particles 
and ferruginous bodies. Methods for quantitating them and some results from the lungs of city dwellers. Arch Environ Hith 1970;21:38-46.

${ }^{6}$ Tipton IH, Cook MJ. Trace elements in human tissue Part II Adult subjects from the United States. Health Physics 1963;9:103-45.

${ }^{7}$ Sweet DV, Crouse WE, Crable JV. Chemical and statistical studies of contaminants in urban lungs. $\mathrm{Am}$ Ind $\mathrm{Hyg}$ Ass $J$ 1978;39:515-26.

${ }^{8} \mathrm{Um} \mathrm{C}-\mathrm{H}$. Study of the secular trend in asbestos bodies in lungs in London 1936-66. Br Med J 1971;2:248-51.

${ }^{9}$ Rosen P, Melamed M, Savino A. The "ferruginous body" content of lung tissue: a quantitative study of eighty-six patients. Acta Cytologica 1972;16:207-11.

${ }^{10}$ Anjilvel L, Thurlbeck WM. The incidence of asbestos bodies in the lungs at random necropsies in Montreal. Canad Med Ass J 1966;95:1179-82.

${ }^{11}$ Cauna D, Totten RS, Gross P. Asbestos bodies in human lungs at autopsy. JAMA 1965;192:371-3.

12 Ashcroft T. Asbestos bodies in routine necropsies on Tyneside: a pathological and social study. $\mathrm{Br}$ Med $J$ $1968 ; 1: 614-8$.

${ }^{13}$ Doniach I, Swettenham KV, Hathorn MKS. Prevalence of asbestos bodies in a necropsy series in Fast London: association with disease, occupation and domicillary address. Br J Ind Med 1975;32:16-30.
${ }^{14}$ Utidjian MD, Gross P, de Treville RTP. Ferruginous bodies in human lung. Arch Environ Hlth 1968;17:327-33.

${ }^{15}$ Warnock ML, Churg AM. Association of asbestos and bronchogenic carcinoma in a population with low asbestos exposure. Cancer $1975 ; 35: 1236-42$.

${ }^{16}$ Oldham PD. A trial of techniques for counting asbestos bodies in tissue. In: Bogovski $\mathrm{P}$ et al, eds. Biological effects of asbestos. Lyons: The International Agency for Research on Cancer, 1973:45-9.

${ }^{17}$ Ashcroft T, Heppleston AG. The optical and electron microscopic determination of pulmonary asbestos fibre concentration and its relation to the human pathological reaction. J Clin Pathol 1973 ;26:224-34.

${ }^{18}$ Dicke TE, Naylor B. Prevalence of "asbestos" bodies in human lungs at necropsy. Dis Chest 1969;56:122-5.

${ }^{19}$ Auerbach O, Constan AS, Garfinkel L, Parks VR, Kaslow HD, Hammond EC. Presence of asbestos bodies in organs other than the lung. Chest 1980;77:133-7.

${ }^{20}$ Francis D, Jussuf A, Mortensen T, Sikjaer B, Viskum K. Hyaline pleural plaques and asbestos bodies in 198 randomised autopsies. Scand J Respir Dis 1977;58:193-6.

${ }^{21}$ Whitwell F, Newhouse ML, Bennett DR. A study of the histological cell types of lung cancer in workers suffering from asbestosis in the United Kingdom. $\mathrm{Br} J$ Ind Med $1974 ; 31: 298-303$ 